\title{
Transcranial magnetic stimulation for treatment of major depression during pregnancy: a review
}

\author{
Estimulação magnética transcraniana para o tratamento de depressão maior \\ durante a gestação: uma revisão
}

Renata de Melo Felipe, ${ }^{1}$ Ygor Arzeno Ferrão ${ }^{2}$

\begin{abstract}
Introduction: Pregnancy is characterized by a high prevalence of mental disorders. Depression is the most common of these disorders and it is a risk factor for negative maternal and child development outcomes. Psychotherapy and pharmacotherapy are conventional and well-established therapeutic options, but some clients fail to respond and the safety of using some pharmacological agents during pregnancy is unclear. Some neuromodulation techniques, such as repetitive transcranial magnetic stimulation (rTMS), have been studied in depressed pregnant women.

Objective: To evaluate the safety and efficacy of rTMS for major depression in pregnant women.

Methods: The LILACS and PubMed databases were reviewed using the search terms depression, pregnancy and magnetic stimulation. Texts including primary data, published in Portuguese, Spanish, or English, between 1995 and 2014, that evaluated depressed pregnant women and used rTMS as the intervention were selected. Papers lacking sufficient data were excluded. Twenty-two texts were initially identified; after applying the inclusion criteria, 12 were selected and analyzed.

Results: The studies reviewed reported satisfactory responses to rTMS in acute depressive episodes, as measured using depressive symptom scales. Remission of symptoms was achieved in many cases. The procedure was well tolerated and there were no reports of damage/complications to unborn children.

Conclusion: The data available at this time support the efficacy and tolerability of rTMS for depression in pregnant women. Controlled studies should corroborate this conclusion. This review only included studies in three languages and the resulting sample size was not large enough to conduct a meta-analysis.

Keywords: Pregnancy, depression, transcranial magnetic stimulation.
\end{abstract}

\section{Resumo}

Introdução: A gestação é caracterizada por uma alta prevalência de transtornos mentais. A depressão é a mais comum entre essas doenças e é fator de risco para desfechos negativos maternos e de desenvolvimento da criança. Psicoterapia e farmacoterapia são opções terapêuticas convencionais e bem estabelecidas, mas algumas pacientes não apresentam resposta, e a segurança do uso de alguns psicofármacos durante a gestação não é clara. Algumas técnicas de neuromodulação, como estimulação magnética transcraniana repetitiva (repetitive transcranial magnetic stimulation, rTMS), vêm sendo estudadas em gestantes com depressão.

Objetivo: Avaliar a segurança e a eficácia da rTMS para depressão maior em mulheres gestantes.

Métodos: As bases de dados LILACS e PubMed foram revisadas utilizando os termos depressão, gestação e estimulação magnética. Textos originais, publicados em português, espanhol, ou inglês, entre 1995 e 2014, que avaliaram gestantes com depressão e utilizaram rTMS como intervenção, foram selecionados. Artigos com dados insuficientes foram excluídos. Vinte e dois textos foram inicialmente identificados; após a aplicação dos critérios de inclusão, 12 foram selecionados e analisados. Resultados: Os estudos revisados demonstraram resposta satisfatória com rTMS em episódios depressivos agudos, avaliada com escalas de sintomas depressivos. Houve remissão em muitos casos. O procedimento foi bem tolerado e não houve relatos de danos/complicações aos bebês.

Conclusão: Os dados disponíveis até o momento sugerem a eficácia e tolerabilidade de rTMS para depressão em gestantes. Estudos controlados devem corroborar esta conclusão. Esta revisão incluiu apenas estudos em três idiomas e resultou em um tamanho amostral insuficiente para conduzir uma metanálise.

Descritores: Gestação, depressão, estimulação magnética transcraniana.

\footnotetext{
${ }_{1}^{1}$ Programa de Residência Médica em Psiquiatria, Universidade Federal de Ciências da Saúde de Porto Alegre (UFCSPA), Porto Alegre, RS, Brazil. ${ }^{2}$ Departamento de Medicina Interna - Psiquiatria, UFCSPA, Porto Alegre, RS, Brazil.

Financial support: none.

Submitted Nov 21 2015, accepted for publication Mar 16 2016. No conflicts of interest declared concerning the publication of this article.

Suggested citation: Felipe RM, Ferrão YA. Transcranial magnetic stimulation for treatment of major depression during pregnancy: a review. Trends Psychiatry Psychother. 2016;38(4):190-197. http://dx.doi.org/10.1590/2237-6089-2015-0076
} 


\section{Introduction}

Pregnancy and the postpartum period involve several changes to a woman's life cycle, with alterations in physical aspects, hormonal parameters, psychological functioning, and social inclusion and these factors can be directly related to mental health. ${ }^{1,2}$ As a result, this is one of the periods during which women are most prone to developing mental disorders, especially during the first and third trimesters of pregnancy. ${ }^{3}$

Although only 5 to $8 \%$ of pregnant women meet criteria for major depressive disorder, ${ }^{4}$ about $20 \%$ of women may experience depressive symptoms during pregnancy and postpartum and this situation often goes undiagnosed and untreated. ${ }^{4-6}$ This is an important risk factor for postnatal depression and evidence suggests that gestational depression may be associated with several negative outcomes, such as low birth weight, preterm birth, and abnormal child development. ${ }^{5-8}$

Conventional treatment options for depression include psychotropicagents (especially antidepressants), psychotherapy, and electroconvulsive therapy (ECT), which is indicated in the most severe or treatmentrefractory cases.

The choice of therapy takes into account the severity of depressive disorder, response to previous treatments, comorbidities, the period of pregnancy, and the pregnant woman and her family's decision. Psychotherapy is an option in less severe cases of disease and can be combined with other measures, such as psychotropic drugs. However, it is well established that it is not appropriate to discontinue pharmacological treatment in more severe, recurrent cases, because of the risks involved (e.g., suicide). 6 Such situations require a complex decision-making process that involves the patient, the family, the obstetrician, and the psychiatrist. $^{9}$

When use of psychotropic drugs in pregnancy is under consideration, the possible risks of antidepressant use must be explained to patients, since many of these agents have not been fully studied and cannot be considered completely safe in pregnancy. ${ }^{10}$ Although some authors report that antidepressants can cause fetal and neonatal toxicity, with results that include intrauterine death, physical malformations, growth impairment, and behavioral teratogenicity, ${ }^{11,12}$ findings appear to be contradictory. There are not yet enough rigorous, well-designed, controlled studies available in the literature to confirm that antidepressants really are dangerous. ${ }^{11}$ The Food and Drug Administration (FDA) currently assign antidepressants to Pregnancy Risk Category B (reproductive studies with animals have failed to demonstrate risk to the fetus and there are no adequate and well-controlled studies with pregnant women). ${ }^{13}$

The most commonly used antidepressants during pregnancy are the selective serotonin reuptake inhibitors (SSRIs). ${ }^{14}$ Although some meta-analyses have provided risk estimates that have not been confirmed at the same magnitude in some other studies, we do know that SSRI use may be related, for example, to pulmonary hypertension; although the risk of persistent pulmonary hypertension of the newborn is low, use of SSRIs in late pregnancy increases that risk more than twofold. ${ }^{15}$ One meta-analysis found that paroxetine and fluoxetine are associated with a small, but significantly increased risk of major malformations and paroxetine in particular is associated with cardiac malformation. ${ }^{14}$ While a systematic review did not show increased risk of heart defects or minor malformations, it did detect an increased risk of major malformations and miscarriage following the use of SSRIs during pregnancy. ${ }^{16}$ However, leaving depressive disorders untreated during pregnancy can also lead to hazardous situations, such as social isolation of the mother, suicide risk, and negative outcomes in the child, such as low birth weight and preterm birth. $5,6,8$

Given the risks of untreated depressive disorders, the possible risks inherent to the use of psychotropic drugs (antidepressants) during pregnancy, and some pregnant women's refusal to take such drugs, other options for the treatment of depression during pregnancy are necessary and using neuromodulation seems promising. The options available include transcranial magnetic stimulation (TMS), which is a noninvasive method for stimulation of certain brain regions that has been used to treat depression and other psychiatric and neurological comorbidities for the last decade. ${ }^{17}$ There is consistent, high-quality (level A) evidence of its efficacy and tolerability as a treatment for depression. ${ }^{17}$ TMS is based on the general principle that stimulation or inhibition of a cortical target could modulate the brain circuits that mediate functions related to the pathophysiology of depression ${ }^{17}$ with effects on neurotransmitters and synaptic plasticity (via long-term potentiation and long-term depression); the genetic apparatus of neurons, glial cells, and the prevention of neuronal death; dendritic growth and sprouting; and neurotrophic factors. ${ }^{18}$

The evidence suggests that best response is achieved when the intervention is performed for acute episodes and in people less than 65 years old for whom treatment with antidepressants has failed or only achieved a partial response. ${ }^{19}$ TMS has been recommended by the American Psychiatric Association (APA), the Canadian Network for Mood and Anxiety 
(CANMAT), and the World Federation of Societies of Biological Psychiatry (WFSBP) as an alternative option for treating major depression or depression in bipolar disorder. ${ }^{17}$ The United States FDA and the Brazilian Federal Medical Council (Conselho Federal de Medicina, CFM) have approved its use in adults with major depression for whom treatment with at least one antidepressant has failed. ${ }^{17,20}$ TMS could also be used for treatment of major depression in pregnant women, given the prevalence and severity of the disease in this population, the importance of treatment for both mother and child, and the persistent controversies about the risks and benefits of antidepressants in pregnancy.

This systematic review seeks to evaluate and provide an overview of current evidence for the efficacy and safety of TMS for treatment of depression during pregnancy.

\section{Method}

Searches were run on the PubMed/MEDLINE, SciELO, LILACS, and Google Scholar electronic databases (Step 1) using the terms depression, pregnancy, magnetic stimulation, and/or neuromodulation.

Two independent reviewers (RMFS and YAF) conducted an initial selection process based on the titles and abstracts of articles returned by the initial searches (Step 2). Papers were excluded if they were duplicate entries ( $n=44)$, were not based on human research $(n=2)$, were about other psychiatric diagnoses (e.g., bipolar depression, schizophrenia, pain) ( $n=13)$, were about other treatment strategies (e.g., ECT or transcranial direct current stimulation [tDCS] $)(n=11)$, or were about other topics $(n=5)$. The inclusion criteria applied were as follows: original articles published in Portuguese, Spanish, or English; in which the subjects were adult pregnant women who were studied at any point during gestation and who had been diagnosed with major depression; and in which TMS was the study intervention for acute treatment of depression, with or without concomitant psychotropic therapy. If there was disagreement between reviewers about inclusion, the item in question was discussed until final agreement (best estimated diagnosis) was reached.

A careful manual search of these studies' references was then performed (Step 3), but did not yield additional papers.

At this point, after Step 3, 22 publications had been selected. All were read in full (Step 4). Following this step, and as illustrated in Figure 1, 10 papers were excluded: 8 because TMS was used to treat postpartum depression; one because TMS was used as maintenance treatment for depression; and one because it lacked sufficient data for assessment.

Step 1: Keyword searches of databases:

PubMed: 26

SCIELO: 1

LILACS: 1

Google Scholar: 38

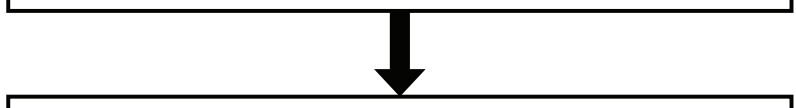

Step 2: Papers retained after application of exclusion criteria*:

PubMed: 22

LILACS, SciELO, Google Scholar: 0

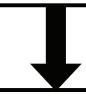

Step 3: After review of references: Additional articles included: 0 PubMed articles retained: 22

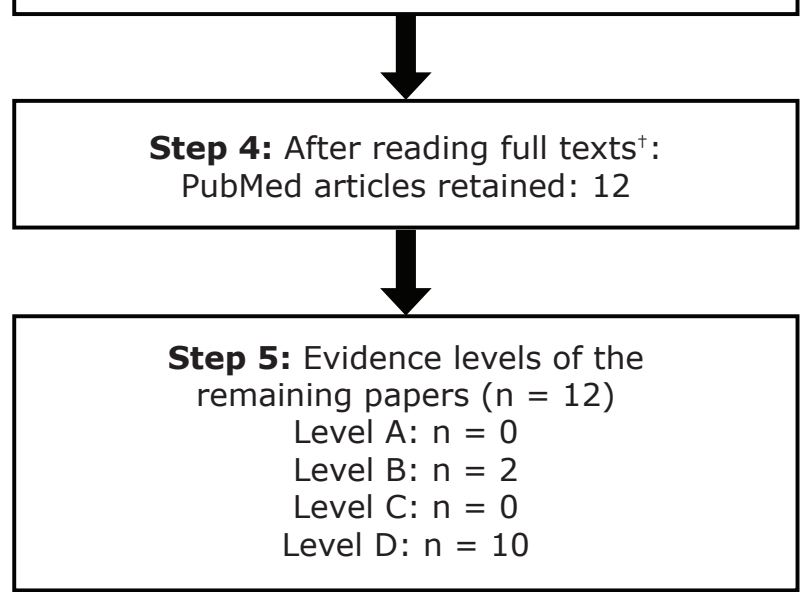

Figure 1 - Flowchart illustrating strategy used to identify papers in the literature about transcranial magnetic stimulation (TMS) for the treatment of major depression during pregnancy. * Repeated $(n=44)$; not human subjects $(n=2)$; about other psychiatric diagnoses (e.g., bipolar depression, schizophrenia, pain) $(n=13)$; about other treatment strategies (e.g., electroconvulsive therapy or transcranial direct current stimulation) $(n=11)$; or about other subjects $(n=5) .{ }^{+}$Eight papers were excluded because TMS was used to treat postpartum depression; one because TMS was used as a maintenance treatment for depression; and one was excluded because data were insufficient for assessment. $\mathrm{n}$ : absolute values.

The papers selected were classified by evidence levels, from $A$ to $D$, with $A$ being the highest level of clinical and epidemiological evidence (Step 5). Articles were stratified by study design as follows: case reports and brief communications (Level D); case series (Level C); open studies and systematic reviews (Level B); and 
randomized controlled trials and meta-analyses (Level A). Case reports that at least subjectively described whether or not there was patient improvement were included even if there was no description of specific systematic evaluation before and after the rTMS treatment (using scales to measure severity of depressive symptoms).

Of the 12 publications selected, 2 were open studies; 2 were brief communications; 1 was a case report; and 7 were original articles that consisted of a case report followed by a review of the technique, but with insufficient description of cases (measures, scales). These open studies and case reports included in the review are summarized in Table 1. All articles were published from 1999 to 2014 and all were in English.

\section{Results and discussion}

\section{Sample and response rate}

The studies included in the review enrolled women at various stages of gestation, from the first to the third trimester, ranging from the 14 th to the 25 th week. ${ }^{21-25}$

Most patients were in an acute episode and symptoms were at least moderate as per Hamilton Rating Scale for Depression and Beck Depression Inventory scores.

The main motivation for choosing TMS was therapeutic failure of psychotropic drugs, persistence of symptoms at least at the moderate level and the nonpharmacological nature of rTMS, which eliminates concerns about fetal exposure to psychotropic medications. ${ }^{26}$ These aspects are consistent with the indications for which U.S. and Brazilian regulatory agencies have approved the use of TMS in major depression. ${ }^{17,20}$

All of the studies included reported a therapeutic response to TMS, except one case report, in which the patient experienced no improvement in depressive symptoms with TMS but responded well to subsequent ECT. ${ }^{22}$ The outcome of this case might suggest that ECT is more effective than TMS in more serious cases, but there is also a possibility that the response occurred as the result of an additive effect of both techniques (TMS followed by $E C T$ ), since the modulation provided by TMS may have served as a facilitator for the effect of ECT. Future, wellconducted, sequential clinical trials may corroborate such a synergistic effect occurring not only with TMS and ECT, but also with TMS and other conventional therapeutic tools, such as psychotherapy and psychopharmaceuticals. ${ }^{27}$

The two open studies with the largest samples reported $41.4 \%$ response, $20.7 \%$ remission, and $34.5 \%$ partial response ${ }^{21}$ and $70 \%$ response and $30 \%$ remission ${ }^{23}$ respectively. These response rates are comparable to the effects of antidepressants. ${ }^{28}$ Both studies defined treatment response as a $>50 \%$ reduction in symptom scale scores. All patients in the other case reports improved or achieved remission. ${ }^{24,25}$

\section{Concomitant medication use}

The samples in the studies selected included women who were on medication, but without an adequate response, and pregnant women not on medication. SSRIs were the most prevalent antidepressant medication. In an open study of 10 pregnant women, four (40\%) were on antidepressant agents: bupropion $300 \mathrm{mg}$ plus escitalopram $20 \mathrm{mg}$, escitalopram $10 \mathrm{mg}$, sertraline $100 \mathrm{mg}$, and fluoxetine 40 mg. ${ }^{23}$ In another open-label study of 30 pregnant women, $12(40 \%)$ were on SSRI monotherapy: 4 (13.3\%) were on escitalopram $30 \mathrm{mg}, 5(16.7 \%)$ were on fluoxetine 20-40 mg, and $3(10 \%)$ were on sertraline $100 \mathrm{mg} .{ }^{21}$ The other 18 patients $(60 \%)$ were not on medication. Two case reports reported use of fluoxetine $20 \mathrm{mg}$ and venlafaxine $225 \mathrm{mg}$ respectively. ${ }^{22,25}$

Continuing antidepressant therapy during TMS could confound measurement of treatment response due to synergistic effects. ${ }^{29}$ However, in the two open studies, the response to TMS seemed effective even when statistically controlling for this confounding variable. Concomitant use of antidepressants was allowed in both studies, but doses had to be stable for at least 2 weeks ${ }^{23}$ or 4 weeks ${ }^{21}$ and could not be changed throughout the study. ${ }^{21,23}$ To date, there have been no specific studies to monitor or evaluate the synergistic effect of TMS and antidepressants in treatment of major depression during pregnancy. There is still no conclusive evidence that TMS works as an add-on treatment for major depression in non-pregnant women. ${ }^{17,30}$ Despite the inconclusive findings of studies about the additive effect of TMS on antidepressants, a metaanalysis of six randomized clinical trials with a total sample of 392 patients showed that the response rate was $43 \%$ for antidepressants in combination with active rTMS and $27 \%$ for antidepressants in combination with placebo rTMS ( $p=$ 0.025). ${ }^{31}$ If an add-on effect of rTMS on antidepressants could be confirmed, its use in depressed pregnant women could be considered, ultimately, as a strategy to reduce doses of psychotropic drugs during pregnancy or even in situations of low tolerance to side effects of this drug class.

Some of the studies in pregnant women included in this review reported therapeutic response even without the use of antidepressants, ${ }^{21,23,24}$ which suggests that TMS may be an important tool for the treatment of depression not only in patients who cannot use or do not tolerate psychotropic agents during pregnancy, but also for those with renal or liver impairment, heart disease, or any other medical conditions that contraindicate use of these drugs. 
Table 1 - Transcranial magnetic stimulation for treatment of major depression during pregnancy: open studies and case reports included in the systematic review

\begin{tabular}{|c|c|c|c|c|c|c|c|c|c|}
\hline \multirow{2}{*}{$\begin{array}{l}\text { Author, type of } \\
\text { study (level of } \\
\text { evidence) }\end{array}$} & \multirow[b]{2}{*}{$\begin{array}{l}\text { Subjects } \\
\text { (n) }\end{array}$} & \multirow[b]{2}{*}{$\begin{array}{l}\text { Concomitant } \\
\text { use of } \\
\text { psychotropics }\end{array}$} & \multicolumn{4}{|c|}{ rTMS parameters } & \multirow[b]{2}{*}{$\begin{array}{l}\text { Improvement/ } \\
\text { measurement } \\
\text { instruments }\end{array}$} & \multirow[b]{2}{*}{$\begin{array}{l}\text { Adverse } \\
\text { effects }\end{array}$} & \multirow[b]{2}{*}{$\begin{array}{l}\text { Neonatal } \\
\text { outcomes }\end{array}$} \\
\hline & & & Laterality & $\begin{array}{l}\text { Motor } \\
\text { threshold }\end{array}$ & Stimulus & $\begin{array}{l}\text { Total } \\
\text { sessions }\end{array}$ & & & \\
\hline $\begin{array}{l}\text { Hızlı Sayar et } \\
\text { al. }{ }^{21} \\
\text { Open-label study } \\
\text { (B) }\end{array}$ & 30 & $\begin{array}{l}12 \text { patients } \\
\text { on SSRI ( } 4 \text { on } \\
\text { escitalopram } \\
30 \mathrm{mg} ; 5 \text { on } \\
\text { fluoxetine } 20- \\
40 \mathrm{mg} ; 3 \text { on } \\
\text { sertraline } 100 \\
\text { mg). } \\
\text { The } 18 \text { other } \\
\text { patients had } \\
\text { been free of } \\
\text { antidepressant } \\
\text { medications for at } \\
\text { least } 4 \text { weeks. }\end{array}$ & Unilateral & $100 \%$ & $\begin{array}{l}6 \text { days } \\
\text { a week: } \\
25-\mathrm{Hz} \\
\text { stimulation } \\
\text { (duration } \\
\text { of } 2 \mathrm{~s}, 20 \\
\text { times, } 30 \mathrm{~s} \\
\text { intervals); } \\
\text { DLPFC: } \\
1,000 \\
\text { pulses per } \\
\text { session }\end{array}$ & 18 & $\begin{array}{l}41.4 \% \text { response; } \\
20.7 \% \text { remission; } \\
34.5 \% \text { partial } \\
\text { response }\end{array}$ & None & $\begin{array}{l}\text { Born at > } \\
36 \text { weeks } \\
\text { gestational } \\
\text { age. } \\
\text { Mean 1-min } \\
\text { Apgar } 8.1 \text { and } \\
\text { mean 5-min } \\
\text { Apgar } 8.8 . \\
\text { Complete } \\
\text { physical and } \\
\text { neurologic } \\
\text { examinations } \\
\text { were normal. } \\
\text { None had } \\
\text { congenital } \\
\text { hip dysplasia, } \\
\text { congenital } \\
\text { cardiac } \\
\text { disease, cleft } \\
\text { lip, or cleft } \\
\text { palate. }\end{array}$ \\
\hline $\begin{array}{l}\text { Gahr et al. } 22 \\
\text { Case report (D) }\end{array}$ & 1 & Fluoxetine $20 \mathrm{mg}$ & Unilateral & $110 \%$ & $\begin{array}{l}5 \text { days } \\
\text { a week: } \\
15 \mathrm{~Hz} ; \\
\text { (duration of } \\
2 \mathrm{~s} \text {, interval } \\
\text { of } 8 \mathrm{~s} \text { ); } \\
\text { DLPFC: } \\
2,970 \\
\text { pulses per } \\
\text { day }\end{array}$ & 25 & $\begin{array}{l}\text { No amelioration } \\
\text { of depressive } \\
\text { symptoms was } \\
\text { achieved over the } \\
\text { course of the first } \\
10 \text { sessions. }\end{array}$ & None & $\begin{array}{l}\text { Not } \\
\text { mentioned }\end{array}$ \\
\hline $\begin{array}{l}\text { Kim et al. }{ }^{23} \\
\text { Open-label study } \\
\text { (B) }\end{array}$ & 10 & $\begin{array}{l}4 \text { subjects } \\
\text { were on } \\
\text { antidepressants } \\
\text { (bupropion SR } \\
300 \mathrm{mg} \text { and } \\
\text { escitalopram } 20 \\
\text { mg; escitalopram } \\
10 \mathrm{mg} \text {; sertraline } \\
100 \mathrm{mg} \text {; } \\
\text { fluoxetine } 40 \\
\text { mg). }\end{array}$ & Unilateral & $100 \%$ & $\begin{array}{l}20 \text { sessions } \\
\text { of } 1-\mathrm{Hz}: 1 \\
\text { Hz; right } \\
\text { DLPFC; } \\
120 \text { pulses/ } \\
\text { session } \\
\text { total of } \\
6000 \text { pulses }\end{array}$ & 20 & $\begin{array}{l}70 \% \text { of subjects } \\
\text { responded; } 30 \% \\
\text { remission }\end{array}$ & $\begin{array}{l}\text { Mild } \\
\text { headache } \\
\text { was the } \\
\text { only } \\
\text { common } \\
\text { adverse } \\
\text { event, } \\
\text { reported } \\
\text { by } 4 \text { out } \\
\text { of } 10 \\
\text { subjects } \\
(40 \%) \text {. }\end{array}$ & $\begin{array}{l}\text { No adverse } \\
\text { pregnancy } \\
\text { or fetal } \\
\text { outcomes } \\
\text { were } \\
\text { observed. All } \\
\text { infants were } \\
\text { admitted } \\
\text { to the } \\
\text { nursery and } \\
\text { discharged } \\
\text { with the } \\
\text { mother. }\end{array}$ \\
\hline $\begin{array}{l}\text { Zhang et al. }{ }^{24} \\
\text { Brief } \\
\text { communication } \\
\text { (D) }\end{array}$ & 1 & None & $\begin{array}{l}\text { First } \\
\text { course: } \\
\text { Unilateral } \\
\text { Second } \\
\text { course: } \\
\text { Bilateral } \\
\text { Third } \\
\text { course: } \\
\text { Bilateral }\end{array}$ & $\begin{array}{l}\text { First } \\
\text { course: } \\
90 \% \\
\text { Second } \\
\text { course: } \\
90 \% \\
\text { Third } \\
\text { course: } \\
90 \%\end{array}$ & $\begin{array}{l}\text { First } \\
\text { course: } 1 \\
\text { Hz; } 1200 \\
\text { pulses/ } \\
\text { session; left } \\
\text { DLPFC } \\
\text { Second } \\
\text { course: } 1 \\
\text { Hz; } 1200 \\
\text { pulses/ } \\
\text { session; } \\
\text { left and } \\
\text { right DLPFC } \\
\text { Third } \\
\text { course: } 1 \\
\text { Hz; 1200 } \\
\text { pulses/ } \\
\text { session; left } \\
\text { and right } \\
\text { DLPFC }\end{array}$ & $\begin{array}{l}\text { First } \\
\text { course: } 10 \\
\text { Second } \\
\text { course: } 10 \\
\text { Third } \\
\text { course: } 10\end{array}$ & $\begin{array}{l}\text { Hamilton } \\
\text { Depression Rating } \\
\text { Scale } \\
\text { After first course: } \\
\text { Initial: } 35 \\
\text { Final: } 12 \\
\text { After second } \\
\text { course: } \\
\text { Initial: } 18 \\
\text { Final: } 8 \\
\text { After third course: } \\
\text { Initial:? } \\
\text { Final: } 8\end{array}$ & None & $\begin{array}{l}\text { No adverse } \\
\text { pregnancy } \\
\text { or fetal } \\
\text { outcomes } \\
\text { were } \\
\text { observed. }\end{array}$ \\
\hline $\begin{array}{l}\text { Klirova et al. }{ }^{25} \\
\text { Brief } \\
\text { communication } \\
\text { (D) }\end{array}$ & 2 & $\begin{array}{l}\text { Patient } 1 \text { : } \\
\text { Venlafaxine } 225 \\
\text { mg, escitalopram } \\
15 \text { mg } \\
\text { Patient 2: } \\
\text { Venlafaxine } 225 \\
\text { mg }\end{array}$ & $\begin{array}{l}\text { Patient 1: } \\
\text { Unilateral } \\
\text { Patient 2: } \\
\text { Unilateral }\end{array}$ & $\begin{array}{l}\text { Patient 1: } \\
100 \% \\
\text { Patient 2: } \\
100 \%\end{array}$ & $\begin{array}{l}\text { Patient } \\
1: 20 \\
\mathrm{~Hz} ; 2000 \\
\text { pulses/ } \\
\text { session; } \\
\text { Left DLPFC } \\
\text { Patient 2: } \\
1 \mathrm{~Hz} ; 300 \\
\text { pulses/ } \\
\text { session; } \\
\text { right DĹPFC }\end{array}$ & $\begin{array}{l}\text { Patient 1: } \\
15 \\
\text { Patient 2: } \\
15\end{array}$ & $\begin{array}{l}\text { One patient in } \\
\text { full remission, } \\
\text { the other with } \\
\text { successful } \\
\text { response ( } 59 \% \\
\text { reduction in } \\
\text { Beck Depression } \\
\text { Inventory) }\end{array}$ & None & $\begin{array}{l}\text { One child } \\
\text { born } \\
\text { premature } \\
\text { ( } 36 \text { weeks) }\end{array}$ \\
\hline
\end{tabular}

$\%=$ relative value; DLPFC = dorsolateral prefrontal cortex; $\mathrm{Hz}=$ Hertz; min = minute; mg = milligrams; $\mathrm{MT}=\mathrm{motor}$ threshold; $\mathrm{n}=$ absolute value; rTMS = repetitive transcranial magnetic stimulation; $\mathrm{s}=\mathrm{seconds}$; SR = slow-release; SSRI = selective serotonin reuptake inhibitor. 
Many serious medical illnesses correlate with depressive syndromes, and in most of these scenarios there are important restrictions to antidepressant treatment. Most antidepressants are metabolized by cytochrome P450, leading to drug interactions with medications used for treatment of the underlying clinical condition. Furthermore, the adverse effects of antidepressants can exacerbate physical symptoms of clinical disease, increasing the risk of treatment discontinuation. ${ }^{32}$ However, precise formal indications for use of TMS in these populations have not yet been established.

\section{TMS technique}

Treatment protocol parameters were quite varied across the studies included. In relation to the anatomical target of application, authors used the right dorsolateral prefrontal cortex, left dorsolateral prefrontal cortex, and bilateral dorsolateral prefrontal cortices.

The initial hypothesis for targeting the dorsolateral prefrontal cortex (DLPFC) would be that this region, which is related to functions such as mood, appetite, and energy, could be hypoactive in depressed individuals. Moreover, the DLPFC is connected to brain areas related to fear and anxiety, such as the amygdala and limbic structures. ${ }^{33}$ Furthermore, the DLPFC is one of the brain regions that are within easy reach of the TMS procedure. The change in DLPFC neuron polarization produced by TMS is presumed to increase blood flow and metabolism of these (previously hypoactive) regions and influence other neurotransmitter systems, neurotrophic factors, and cortical excitability, thus accounting for the antidepressant effect of DLPFC stimulation. ${ }^{18,34-36}$

Based on the concept of asymmetry of frontal cortical activity in depression, there are two lines of research for the use of TMS in depression: low-frequency stimulation (neural inhibition-inducing) on the right DLPFC, which is presumably hyperactive in depression, and high-frequency stimulation (putatively neural excitation-inducing) on the left DLPFC, which is presumably hypoactive in depression. A combination of the two may also be used. ${ }^{37-39}$

The frequency of stimulation is related to the side of application. Studies in pregnant women with depression reported using $10-25 \mathrm{~Hz}$ in the left DLPFC and $1 \mathrm{~Hz}$ in the right DLPFC, which are very similar to the frequencies used in depression protocols in non-pregnant adults. ${ }^{40-44}$

The number of sessions ranged from one session every 2 weeks (for maintenance sessions) to 3-5 sessions per week (for acute episodes).

Due to the limited number of studies and the heterogeneity of protocols, the exact cortical site of stimulation and frequency associated with optimal results and superior efficacy in pregnant women with depression cannot be determined. However, studies in pregnant women seek to reproduce the protocols used for adult non-pregnant women.

\section{Adverse effects}

No major adverse effects of rTMS were reported in the studies reviewed. One of the open studies found no adverse effects; TMS was well tolerated, with a dropout rate of $3.3 \%(n=1)$, which was not due to a side effect. ${ }^{21}$ The other open study observed no serious adverse events, with mild headache being the only adverse effect reported, occurring in $4(40 \%)$ out of 10 pregnant women. ${ }^{23}$ This symptom lasted for 1 to 2 hours after the session during the first week of treatment. This study monitored vital signs before and after treatment, and no changes in heart rate or blood pressure were observed. The treatment adherence rate was $100 \%$ and there were no dropouts. The dropout rates reported are considered low when compared to those of antidepressants, which have ranged from $4.2 \%$ in the elderly ${ }^{45}$ to $20-27 \%$ in adults ${ }^{46}$ in clinical trials.

Tolerability is an important advantage of TMS over other therapeutic modalities based on neuromodulation, especially ECT. The most significant advantages of TMS are its localized effect on the target brain region and no need for general anesthesia, therefore lowering fetal exposure to chemical substances as a result of the procedure. Furthermore, ECT may cause temporary memory loss and requires a recovery period under observation, whereas with TMS patients can quickly resume their activities after the procedure. ${ }^{21,47}$

Regarding adverse cognitive effects, it is well known that the pathophysiology of psychiatric disorders such as depression and schizophrenia involves a negative impact on cognitive functions. Unlike ECT, TMS appears to improve cognitive function. ${ }^{48}$ On the other hand, the response of depressive symptoms to ECT is presumed to be more general and robust. ${ }^{49}$

\section{Fetal outcomes}

There were no reports of immediate abnormalities at birth or negative fetal outcomes. In studies with larger samples, there were no changes in parameters such as Apgar score, prematurity, or hospital discharge of the infant concomitantly with the mother. ${ }^{21}$

One case report described preterm labor at 36 weeks, but it is not known whether this outcome was secondary to TMS treatment, since the patient was on concomitant venlafaxine therapy; to date, this is one of the few complications of TMS reported in the literature. ${ }^{25}$

These findings corroborate the data from a recent follow-up study of children whose mothers had 
undergone TMS during pregnancy, which reported preliminary results of no statistically significant difference in neurodevelopmental parameters when compared to a control group. ${ }^{26}$ In that study, Eryilmaz et al. confirmed that rTMS exposure during pregnancy was not associated with poorer cognitive or motor development outcomes in children aged 18-62 months. ${ }^{26}$ Nevertheless, the same authors found higher mother's perception of language delay, which was the same in the rTMS-treated group and in the untreated mothers with prenatal depression. ${ }^{26}$ These results may reflect: 1 ) a possible side effect of rTMS on the newborn; or 2) that depression per se could have negative consequences on later language development, and that rTMS was not effective for reverting it. The association of rTMS and language delay needs further investigation with adequate attention to methodological and sampling design.

Based on current knowledge of neurophysiology, the coil-induced magnetic field would not have enough power to affect the fetus directly, as the maximum depth of penetration of the magnetic field is approximately 5 to $7 \mathrm{~cm} .^{50}$

\section{Final considerations}

Although the papers reviewed were carefully assessed for reported efficacy and safety of TMS, studies with lower levels of clinical and epidemiological evidence (such as case reports and brief communications) had to be included in this review and the number of high-quality studies was insufficient to perform a meta-analysis or to enable TMS to be classified among therapeutic strategies with level A evidence for treatment of major depression during pregnancy.

On the basis of the current literature, TMS can be considered an effective therapeutic alternative for treatment of depression in pregnant women, especially in cases with no satisfactory response to prior antidepressant trials or when the pregnant woman, her family, or her obstetrician object to the use of drugs during pregnancy. Regarding safety, there have been no recorded cases of malformations or other negative fetal outcomes, but mild maternal discomfort during application of the technique has been reported. In light of the foregoing, we consider the evidence base for rTMS in depression during pregnancy as still incipient (evidence level $\mathrm{C}$ ). This conclusion may be due to the scant evidence extracted from the literature, but also due to some limitations of this review, which only included studies in three languages and did not achieve a sufficient sample size to conduct a meta-analysis. We were also unable to find any case reports or studies with negative results, which could "balance" adequately the efficacy of rTMS in depressed pregnant women.

Despite promising findings, adequate studies with larger samples, double-blinded and controlled strategies, well-designed rTMS parameters, and even prospective protocols (follow-up of pregnant women and their children) are still needed to further endorse the efficacy and safety of TMS before this method can be supported by a higher level of evidence.

\section{References}

1. Pereira PK, Lovisi GM. Prevalência da depressão gestacional e fatores associados. Rev Psiquiatr Clin. 2008;35:144-53.

2. Araujo DM, Vilarim MM, Sabroza AR, Nardi AE. [Depression during pregnancy and low birth weight: a systematic literature review]. Cad Saude Publica. 2010;26:219-27.

3. Botega, NJ, Dias MK. Gravidez e puerpério. In: Botega NJ, editor Prática psiquiátrica no hospital geral: interconsulta e emergência. Porto Alegre, Artmed; 2006. p. 341-54.

4. Bennett HA, Einarson A, Taddio A, Koren G, Einarson TR. Prevalence of depression during pregnancy: systematic review. Obstet Gynecol. 2004;103:698-709.

5. Patel V, Prince M. Maternal psychological morbidity and low birth in India. Br J Psychiatry. 2006;188:284-5.

6. Rahman A, Iqbal Z, Bunn J, Lovel H, Harrington R. Impact of maternal depression on infant nutritional status and illness: a cohort study. Arch Gen Psychiatry. 2004;61:946-52.

7. Ciesielski TH, Marsit CJ, Williams SM. Maternal psychiatric disease and epigenetic evidence suggest a common biology for poor fetal growth. BMC Pregnancy Childbirth. 2015;15:192.

8. Nulman I, Koren G, Rovet J, Barrera M, Streiner DL, Feldman BM. Neurodevelopment of children prenatally exposed to selective reuptake inhibitor antidepressants: Toronto sibling study. J Clin Psychiatry. 2015;76:e842-7.

9. Nygaard $L$, Rossen CB, Buus N. Balancing risk: a grounded theory study of pregnant women's decisions to (dis) continue antidepressant therapy. Issues Ment Health Nurs. 2015;36:485-92.

10. Ram D, Gandotra S. Antidepressants, anxiolytics, and hypnotics in pregnancy and lactation. Indian J Psychiatry. 2015;57:S354-71.

11. Camacho RS, Cantinelli FS, Ribeiro CS, Cantilino A, Gonsales BK, Braguittoni $E$, et al. Transtornos psiquiátricos na gestação e no puerpério: classificação, diagnóstico e tratamento. Rev Psiquiatr Clin. 2006;33:92-102.

12. Sutter-Dallay $A L$, Bales $M$, Pambrun $E$, Glangeaud-Freudenthal $\mathrm{NM}$, Wisner $\mathrm{KL}$, Verdoux $\mathrm{H}$. Impact of prenatal exposure to psychotropic drugs on neonatal outcome in infants of mothers with serious psychiatric illnesses. J Clin Psychiatry. 2015;76:967-73.

13. Boothby LA, Doering PL. FDA labeling system for drugs in pregnancy. Ann Pharmacother. 2001;35:1485-9.

14. Myles $\mathrm{N}$, Newall $\mathrm{H}$, Ward $\mathrm{H}$, Large $M$. Systematic meta-analysis of individual selective serotonin reuptake inhibitor medications and congenital malformations. Aust $\mathrm{N} Z \mathrm{Z}$ Psuchiatry. 2013;47:1002-12.

15. Kiele H, Artama M, Engeland A, Ericsson Ö, Furu K, Gissler M, et al. Selective serotonin reuptake inhibitors during pregnancy and risk of persistent pulmonary hypertension in the newborn: population based cohort study from the five Nordic countries. BMJ. 2012;344:d8012.

16. Nikfar S, Rahimi R, Hendoiee N, Abdollah M. Increasing the risk of spontaneous abortion and major malformations in newborns following use of serotonin reuptake inhibitors during pregnancy: a systematic review and updated meta-analysis. Daru. 2012;20:75.

17. Lefaucheur J, André-Obadia N, Antal A, Ayache, SS, Baeken C, Benninger $\mathrm{DH}$, et al. Evidence-based guidelines on the therapeutic use of repetitive transcranial magnetic stimulation (rTMS). Clin Neurophysiol. 2014;125:2150-206.

18. Chervyakov AV, Chernyavsky AY, Sinitsyn DO, Piradov MA. Possible mechanisms underlying the therapeutic effects of transcranial magnetic stimulation. Front Hum Neurosci. 2015;9:303.

19. George MS, Post RM. Daily left prefrontal repetitive transcranial 
magnetic stimulation for acute treatment of medication-resistant depression. Am J Psychiatry. 2011;168:356-64.

20. Conselho Federal de Medician (CFM). Resolução CFM 1.986/2012 [Internet]. 2012 May 02 [cited 2015 Oct]. portalmedico.org.br/ resolucoes/CFM/2012/1986_2012.pdf

21. Hızlı Sayar G, Ozten E, Tufan E, Cerit C, Kağan G, Dilbaz N, et al. Transcranial magnetic stimulation during pregnancy. Arch Womens Ment Health. 2014;17:311-5.

22. Gahr M, Blacha C, Connemann BJ, Freudenmann RW, SchönfeldtLecuona C. Successful treatment of major depression with electroconvulsive therapy in a pregnant patient with previous nonresponse to prefrontal rTMS. Pharmacopsychiatry. 2012;45:79-80.

23. Kim DR, Epperson N, Pare E, Gonzalez JM, Parry S, Thase ME, et al. An open label pilot study of transcranial magnetic stimulation for pregnant women with major depressive disorder. J Womens Health (Larchmt). 2011;20:255-61.

24. Zhang X, Liu K, Sun J, Zheng Z. Safety and feasibility of repetitive transcranial magnetic stimulation (rTMS) as a treatment for major depression during pregnancy. Arch Womens Ment Health. 2010;13:369-70.

25. Klirova M, Novak T, Kopecek M, Mohr P, Strunzova V. Repetitive transcranial magnetic stimulation (rTMS) in major depressive episode during pregnancy. Neuro Endocrinol Lett. 2008;29:69-70.

26. Eryilmaz G, Sayar GH, Özten E, Gül IG, Yorbik Ö, Isiten N, et al. Follow-up study of children whose mothers were treated with transcranial magnetic stimulation during pregnancy: preliminary results. Neuromodulation. 2015;18:255-60.

27. Collins LM, Murphy SA, Strecher V. The Multiphase Optimization Strategy (MOST) and the Sequential Multiple Assignment Randomized Trial (SMART): new methods for more potent health interventions. Am J Prev Med. 2007;32:S112-8.

28. Rush AJ. Star-D: lessons learned and future implications. Depress Anxiety. 2011;28:521-4.

29. Berlim MT, McGirr A, Beaulieu MM, Turecki G. High frequency repetitive transcranial magnetic stimulation as an augmenting strategy in severe treatment-resistant major depression: a prospective 4-week naturalistic trial. J Affect Disord. 2011;130:312-7.

30. Prasser J, Schecklmann M, Poeppl TB, Frank E, Kreuzer PM, Hajak $\mathrm{G}$, et al. Bilateral prefrontal rTMS and theta burst TMS as an addon treatment for depression: a randomized placebo controlled trial. World J Biol Psychiatry. 2015;16:57-65.

31. Berlim MT, Van den Eynde F, Daskalakis ZJ. High-frequency repetitive transcranial magnetic stimulation accelerates and enhances the clinical response to antidepressants in major depression: a meta-analysis of randomized, double-blind, and sham-controlled trials. J Clin Psychiatry. 2013;74:e122-9.

32. Valiengo LC, Bensen IM, Lotufo PA, Fraguas Jr R, Brunoni AR. Transcranial direct current stimulation and repetitive transcranial magnetic stimulation in consultation-liaison psychiatry. Braz J Med Biol Res. 2013;46:815-23.

33. Banks SJ, Eddy KT, Angstadt M, Nathan PJ, Phan KL. Amygdalafrontal connectivity during emotion regulation. Soc Cogn Affect Neurosci. 2007:2:303-12.

34. Kimbrell TA, Little JT, Dunn RT, Frye MA, Greenberg BD, Wassermann $E M$, et al. Frequency dependence of antidepressant response to left prefrontal repetitive transcranial magnetic stimulation (rTMS) as a function of baseline cerebral glucose metabolism. Biol Psychiatry. 1999;46:1603-13.

35. Nobler MS, Teneback CC, Nahas Z, Bohning DE, Shastri A, Kozel FA, et al. Structural and functional neuroimaging of electroconvulsive therapy and transcranial magnetic stimulation. Depress Anxiety. 2000;12:144-56.

36. Janicak PG, Dokucu ME. Transcranial magnetic stimulation for the treatment of major depression. Neuropsychiatr Dis Treat. 2015;11:1549-60.

37. Klein E, Kreinin I, Chistyakov A, Koren D, Mecz L, Marmur S, et al.
Therapeutic efficacy of right prefrontal slow repetitive transcranial magnetic stimulation in major depression: a double-blind controlled study. Arch Gen Psychiatry. 1999;56:315-20.

38. George MS, Nahas Z, Molloy M, Speer AM, Oliver NC, Li XB, et al. A controlled trial of daily left prefrontal cortex TMS for treating depression. Biol Psychiatry. 2000;48:962-70.

39. Speer AM, Kimbrell TA, Wassermann EM, D Repella J, Willis MW, Herscovitch $P$, et al. Opposite effects of high and low frequency rTMS on regional brain activity in depressed patients. Biol Psychiatry. 2000;48:1133-41.

40. Lisanby $\mathrm{SH}$, Husain MM, Rosenquist PB, Maixner D, Gutierrez $R$, Krystal A, et al. Daily left prefrontal repetitive transcranial magnetic stimulation in the acute treatment of major depression: clinical predictors of outcome in a multisite, randomized controlled clinical trial. Neuropsychopharmacology. 2009;34:522-34.

41. Triggs WJ, Ricciuti N, Ward HE, Cheng J, Bowers D, Goodman WK, et al. Right and left dorsolateral pre-frontal rTMS treatment of refractory depression: a randomized, sham-controlled trial. Psychiatry Res. 2010;178:467-74.

42. Fitzgerald PB, Hoy $K$, McQueen S, Herring S, Segrave R, Been $G$, et al. Priming stimulation enhances the effectiveness of lowfrequency right prefrontal cortex transcranial magnetic stimulation in major depression. J Clin Psychopharmacol. 2008;28:52-8.

43. Baeken C, Vanderhasselt MA, Remue J, Herremans S, Vanderbruggen $\mathrm{N}$, Zeeuws $\mathrm{D}$, et al. Intensive HF-rTMS treatment in refractory medication-resistant unipolar depressed patients. J Affect Disord. 2013;151:625-31.

44. Ray S, Nizamie SH, Akhtar S, Praharaj SK, Mishra BR, Ziaul-Haq M. Efficacy of adjunctive high frequency repetitive transcranial magnetic stimulation of left prefrontal cortex in depression: a randomized sham controlled study. J Affect Disord. 2011;128:153-9.

45. Kok RM, Heeren TJ, Nolen WA. Continuing treatment of depression in the elderly: a systematic review and meta-analysis of doubleblinded randomized controlled trials with antidepressants. Am J Geriatr Psychiatry. 2011;19:249-55.

46. Warden D, Rush AJ, Wisniewski SR, Lesser IM, Kornstein SG, Balasubramani GK, et al. What predicts attrition in second step medication treatments for depression? a STAR*D Report. Int J Neuropsychopharmacol. 2009;12:459-73.

47. Rosa AM, OdebrechtM, RigonattiSP, Marcolin MA. Eletroconvulsoterapia e estimulação magnética transcraniana: semelhanças e diferenças. Rev Psiquiatr Clin. 2004;31:243-50.

48. Serafini G, Pompili M, Belvederi Murri M, Respino M, Ghio L, Girard $P$, et al. The effects of repetitive transcranial magnetic stimulation on cognitive performance in treatment-resistant depression. A systematic review. Neuropsychobiology. 2015;71:125-39.

49. Micallef-Trigona B. Comparing the effects of repetitive transcranial magnetic stimulation and electroconvulsive therapy in the treatment of depression: a systematic review and meta-analysis. Depress Res Treat. 2014:135049. Epub 2014 Jul 21.

50. GeorgeMS, Nahas Z, Kozel FA, Li X, Denslow S, Yamanaka K, et al. Mechanisms and state of the art of transcranial magnetic stimulation. J ECT. 2002;18:170-81.

\section{Correspondence:}

Ygor A. Ferrão

Rua Padre Chagas, 185 Sala 902, Moinhos de Vento

90570-080 - Porto Alegre, RS - Brazil

Tel.: +55 (51) 3346.1077

E-mail: ygoraf@ufcspa.edu.br 